\title{
ENSINO DO MÉTODO DE PLANEJAMENTO ESPACIAL - CONSIDERAÇÕES SOBRE A INVESTIGAÇÃO DO TERRITÓRIO E DO USUÁRIO NO DESIGN DE INTERIORES
}

\author{
ENVIRONMENT PLANNING METHOD - TERRITORY AND USER \\ INVESTIGATION CONSIDERATIONS IN INTERIOR DESIGN
}

\author{
Gilberto Rangel de Oliveira ${ }^{1}$, D.Sc. \\ Luiz Paulo Barbosa da Costa ${ }^{2}$, graduando \\ Julia Lamoglia Simas Pinna ${ }^{3}$, graduanda \\ (1) Universidade Federal do Rio de Janeiro - UFRJ \\ gilbertorangel@eba.ufrj.br \\ (2) Universidade Federal do Rio de Janeiro - UFRJ \\ luizpaulocosta13@yahoo.com.br \\ (3) Universidade Federal do Rio de Janeiro - UFRJ \\ pinnajulia@gmail.com
}

\section{Metodologia projetual Território, Conceito}

O método de Planejamento Espacial é empregado como instrumento facilitador de ensino da disciplina Composição de Interiores I, na Escola de Belas Artes - UFRJ. São descritas as etapas do método, com enfoque no usuário e território. O resultado desse mapeamento teórico produz um conceito e o partido de projeto, elementos essenciais na elaboração do projeto gráfico de design de interiores.

\section{Design methodology, Territory, Concept}

The Spatial Planning method is used as an instrument to facilitate the teaching of Interior Composition I, at the School of Fine Arts - UFRJ. The steps of the method are described, focusing on the user and territory. The result of this theoretical mapping produces a concept and the design party, essential elements in the elaboration of the graphic design of interior design.

\section{A Atividade Design de Interiores}

O design de interiores ${ }^{1}$ é uma atividade que se dedica à criação de interfaces entre os usuários e as edificações os quais habitam e onde realizam suas atividades. Brooker e Stone (2014, p. 12) explicam que o design de interiores (ou projeto de interiores) é uma atividade multidisciplinar que envolve a criação de ambientes internos que articulam o clima e a identidade por meio da manipulação dos volumes espaciais, da colocação de elementos específicos e mobiliário, além do tratamento das superfícies. "Em geral, descreve projetos que requerem poucas mudanças estruturais - ou

\footnotetext{
${ }^{1}$ Utiliza-se aqui o termo design de interiores e as atribuições funcionais do designer de interiores conforme adotado na Regulamentação da Profissão, LEI N ${ }^{\circ}$ 13.369/16 sancionada em 13/12/2016. Também se utiliza o termo projeto de interiores (utilizado por alguns
}

nenhuma - na construção já existente, embora haja muitas exceções". O espaço é mantido em seu estado estrutural original e o novo interior é nele inserido.

Os autores fazem também uma distinção entre os termos decoração de interiores e arquitetura de interiores $^{2}$. O primeiro trata-se da arte de decorar espaços interiores - cômodos ou ambientes - para transmitir uma identidade característica que funciona bem com a arquitetura existente. Está relacionada com padrões de superfícies, ornamentos, mobiliário, acessórios, iluminação e materiais. O segundo termo preocupa-se com a

autores) para designar a mesma atividade, sem prejuízo de suas características próprias.

2 Nota do autor: os termos citados são traduções da publicação de Booker \& Stone (2014) da língua inglesa para o português brasileiro. 
remodelagem das construções e atitudes direcionadas para os espaços e as estruturas existentes, a reutilização de construções e os princípios organizacionais. A arquitetura de interiores conecta as práticas do design de interiores com a arquitetura, e com frequência inclui problemas complexos estruturais, ambientais, de linguagem, ergonômicos, de sustentabilidade, técnicos, entre outros. Neste artigo corrobora-se os argumentos dessa definição e suas consequências.

Considerando-se o número elevado de fatores envolvidos que devem ser considerados e manipulados pelo profissional na ação projetual, para que a realização da atividade alcance êxito, defende-se o uso de uma estratégia metodológica.

A palavra projeto neste artigo corrobora com os escritos de SILVA (1998, p. 39) que explica, projeto para os espaços arquitetônicos é "uma proposta de solução para um problema específico de organização do entorno humano, através de uma determinada forma construtível, bem como a descrição desta forma e as prescrições para sua execução." Entende-se a importância de tratar do projeto enquanto processo, como entendê-lo praticálo e desenvolvê-lo. Desta forma, acredita-se que o projeto em si ainda não é uma solução finalizada do problema de projeto (arquitetônico ou de interiores), pois somente após a realização do trabalho proposto é que se irá satisfazer (ou não) realmente às necessidades dos usuários.

As necessidades dos usuários que se busca satisfazer na realização do projeto de design de interiores estão abrigadas sob dois aspectos principais: funcional e simbólico. Os aspectos funcionais devem contemplar a previsão de espaços necessários às atividades envolvidas e garantir que elas estejam distribuídas de modo apropriado, a fim de facilitar o uso particular. Sendo assim, estes aspectos atendem às demandas de layout, fluxo, organização espacial, conforto térmico, lumínico e acústico, ergonômico, de segurança, materiais para tratamento das superfícies, além de demandas específicas de equipamentos e acessórios previstos para atender o usuário. Os aspectos simbólicos concentram-se em atender às necessidades culturais, a identidade do usuário, aspectos estéticos e ainda, as sensações possíveis de proporcionar ao usuário.

A história da formação de projetistas (em especial arquitetos, designers e designers de interiores) mostra que progressivamente o local de trabalho foi trocado pelo ateliê de projeto das universidades. Lawson (2011) explica que a formação dos profissionais de projeto tem algumas características muito comuns que transcendem os países e os campos de atividade.

Tipicamente, as escolas usam o ateliê físico e conceitual como principal mecanismo de ensino. Em termos conceituais, o estúdio é um processo de aprender fazendo, no qual os alunos recebem uma série de problemas de projeto para resolver. Assim aprendem a projetar principalmente na prática, em vez de empregar estudos ou análises. (LAWSON 2011, p:19)

Contudo, o autor faz sérias críticas quanto ao afastamento do aluno em relacionar dados e realizar reflexões, correlacionar fatos, avaliar todo o processo e aproveitar a tecnologia existente. "Parece quase impossível aprender a projetar sem pôr a mão na massa. Um dos pontos fracos do estúdio tradicional é que os alunos, por dar muita atenção ao produto final do trabalho, deixam de refletir suficientemente sobre o processo." Nesse sentido o autor conclui que, "é fácil o estúdio didático transformar-se num lugar fantasioso e distante das necessidades do mundo real onde os alunos trabalharão quando se formar [...] no processo isso tende a distorcer não só o equilíbrio de habilidades como também o conjunto de valores que os alunos adquirem." Ibid, p. 19.

A aplicação de metodologias de projeto no âmbito do ensino acadêmico é tema amplo com diversas discussões e posições controversas. Os desafios aqui expostos tornam-se ainda mais significativos quando se faz necessário o planejamento didático para exposição de todas as necessidades projetuais do usuário, as complexidades implícitas do problema de projeto e a inexperiência natural de alunos ávidos por conhecimento. Diante deste cenário, é providencial utilizar-se de instrumentos metodológicos que auxiliem o aluno no desenvolvimento do seu trabalho, constituído de algum processo reflexivo. No percurso da disciplina obrigatória Composição de Interiores I, do curso Composição de Interior pertencente à Escola de Belas Artes - EBA, da UFRJ, aplica-se um método analítico divididos por seções específicas relativo à fase inicial do projeto. O método de Planejamento Espacial faz uso de um perfil de usuário fictício único, proposto pelo docente para todo grupo de alunos e de uma edificação residencial de até 100 $\mathrm{m}^{2}$, com planta arquitetônica definida e adequada 
aos padrões legais do Código de Obras da cidade do Rio de Janeiro.

Neste artigo apresenta-se o método de Planejamento Espacial, utilizado como ferramenta didádica pedagógica no ensino de execução de projeto de interiores. Descreve-se as etapas do método, com enfoque especial ao usuário e território, além de apontar a importância da construção de um conceito de projeto. Ao final serão tecidas considerações sobre a aplicação do método em um ambiente acadêmico, considerando os aspectos positivos e negativos.

\subsection{O ensino do design de interiores no Brasil}

De Jean, (2009, p. 74-75) é categórica em afirmar que a revolução que tornou a decoração de interiores um campo publicamente reconhecido foi fruto da criatividade dos arquitetos franceses Blondel e Marriette. A autora explica que em 1738, Marriette publicou o volume final de sua Architecture française, ilustrado em grande parte por gravuras de Blondel, que por sua vez publicou a segunda parte de seu manifesto pela arquitetura moderna - assim os dois trabalhos deram um passo inédito ao incluir, além dos projetos das residências mais famosas (Palais Borboun ${ }^{3}$, por exemplo) da época, as primeiras ilustrações completas e detalhadas da decoração de cômodos, muitas vezes incluindo os móveis.

Pelo menos até meados do século XVIII, os arquitetos eram de modo geral membros de dinastias: Jacques-François Blondel, por exemplo, foi responsável por quase todas as realizações da época do fim da década de 1720 até o início da década de 1770, e foi treinado por seu tio JeanFrançois Blondel. Em 1740, Blondel criou a primeira escola privada de arquitetura, a École des Arts (Escola de Artes), oficialmente sancionada pela Academia Real de Arquitetura francesa em 1743. A escola foi um passo importante no sentido de padronizar o aprendizado da profissão, além disso, como agente disseminador de conhecimento, ensinava profissionais franceses e estrangeiros (entre seus alunos estavam dois dos mais visionários arquitetos do fim do século XVIII, Boullée e Ledoux), e assim, os estrangeiros levavam o estilo da escola francesa para seus países

3 Em 1738, os espaços interiores do Palais Bourbon ainda estavam intactos e Mariette publicou sete gravuras para mostrar a seus leitores exatamente como eram os cômodos. As imagens garantiram o status do palácio
No Brasil, a primeira escola a ministrar o curso de Design de Interiores foi o IAD - Instituto de Artes e Design, em 1959, em São Paulo. Mais tarde surgiram os cursos técnicos de nível médio, como a Escola Técnica Estadual Carlos de Campos - SP e os cursos de bacharelado nas cidades de Uberlândia, Belo Horizonte e Rio de Janeiro - Escola de Belas Artes, UFRJ. Contudo, inicialmente o curso chamava-se "Arquitetura de Interiores", "Decoração de Interiores", "Composição de Interiores" ou apenas "Decoração".

O termo Design de Interiores foi oficializado no final da década de 1990, quando o Ministério da Educação e Cultura (MEC) lançou os "Referenciais Curriculares Nacionais da Educação Profissional de Nível Técnico - Área Design" (Associação Brasileira de Design de Interiores - ABD e Academia Brasileira de Arte - ABRA).

Conforme publicado na página do MEC, na seção Instituições de Educação Superior e cursos cadastrados, atualmente há 263 cursos de Design de Interiores espalhados por todo país, sendo 10 bacharelados e 233 tecnólogos - todos presenciais. Há ainda 20 cursos tecnológicos na modalidade à distância. ${ }^{4}$

Estes dados revelam uma explosão de escolas de design de interiores pelo Brasil. O que por um lado demonstra uma demanda crescente pela área, por outro, expõe a necessidade de investimentos consistentes na qualidade do ensino e especialmente na pesquisa, justo posto para uma atividade que passa por processo de solidificação da profissão. A função de um designer de interiores definida pela International Federation of Interior Architects / Designersand International Design Aliance - IFIIDA (Associação Internacional de Design de Interiores e Aliança Internacional do Design) é defendida através de formação acadêmica, experiência e especialização, definindo que o designer de interiores deve estar qualificado para aprimorar a função e a qualidade dos espaços interiores, com o objetivo de melhorar a qualidade

como um dos primeiros monumentos à decoração de interiores da história. (De Jean, 2012, p. 223)

4 Extraído do portal do MEC: :

<http://emec.mec.gov.br $>$. Acesso em: 30.ago.2019 
PUC-Rio Pontifícia Universidade Católica do Rio de Janeiro Departamento de Artes \& Design | PPGDesign

LEUI | Laboratório de Ergodesign e Usabilidade de Interfaces

de vida, aumentar a produtividade e proteger a saúde, a segurança e o bem-estar público. ${ }^{5}$

\section{Metodologia de Planejamento Espacial}

Método é o caminho para se atingir um determinado objetivo, podendo ser composto de várias técnicas (meios) que facilitem o processo. Pazmino (2015) explica que "o método envolve instrumentos de planejamento, coleta, análise e síntese, caracterização dos instrumentos, materiais com o qual o designer trabalha." Os métodos de projeto não são inimigos da criatividade, imaginação ou intuição - ao contrário, eles conduzem a soluções inovadoras, sendo que alguns métodos são técnicas específicas para auxiliar o pensamento criativo.

Contudo, a autora lembra que "o método pressupõe sistemática de trabalho, organização, e rigor no desenvolvimento do processo, podendo representar os passos aplicados nos processos de design, ou seja, o ato concreto da realização e o caminho." (PAZMINO, 2015, p. 11).

Coelho (2011) lembra que em alguns casos o uso da palavra metodologia no meio acadêmico costuma ter diferentes denominações, com ênfase ao "campo teórico de determinada área ou concentrando-se em grandes áreas, como é o caso de disciplinas que trabalham conteúdos a partir das ciências biológicas, sociais, humanas ou físicas". Os estudos realizados nessas pesquisas costumam contemplar tanto a teoria metodológica em si, quanto sua aplicação em objetos específicos (metodologia aplicada). Neste caso, o estudo de disciplinas com esse entendimento privilegia a chamada metodologia científica "embora trabalhem, por vezes, com procedimentos metodológicos particulares a um campo delimitado". Nesse sentido, corrobora-se com o entendimento do autor sobre metodologia aplicada no campo do design, o qual tem sido empregado na atividade de design de interiores.

É o caso, por exemplo, do curso de Design, em que o chamado método projetual é ensinado. Justifica-se esse tipo de tratamento da disciplina sobre métodos no ensino do design em FUNÇÃO de peculiaridades da profissão, que exige conhecimentos sólidos de PROJETO (COELHO, 2011, p: 252 e 253).

\footnotetext{
5 Extraído do site:

http://www.ifiworld.org/\#Definition_of_an_IA/D .

Acesso em: 30 set. 2019

6 OLIVEIRA, Gilberto Rangel. MÉTODOS DE PROJETO DE INTERIORES NO BRASIL. Revista
}

No sentido de reforçar a importância do uso de métodos de projeto no desenvolvimento de espaços planejados, defendidos nesta pesquisa, traz-se a constatação de Karlen (2010, p. 16), onde o autor afirma que do ponto de vista prático e profissional que o designer precisa de um processo eficiente e confiável ao qual deve recorrer sempre que se deparar com um projeto de design de interiores. "Reunir alguns fatos básicos e ficar olhando para uma planta baixa em branco até que a inspiração surja é uma abordagem totalmente inviável".

Considerando-se as assertivas acima expostas e com o objetivo de compreender a fundo a relação do usuário e o ambiente construído, aplica-se o método de Planejamento Espacial. Esta ferramenta trata de investigar os problemas de projeto durante a etapa do processo de planejamento do ambiente que se inicia assim que os problemas são apresentados ao aluno e termina quando o projeto gráfico (como elemento de linguagem representativa) é elaborado. Esta etapa pertence a fase inicial do projeto, que conforme consenso entre os autores de metodologia projetual no design, compreende: planejamento, análise, síntese e criatividade ${ }^{6}$.

\section{O termo método de Planejamento Espacial tem} inspiração no método "Metodologia de Planejamento", (Karlen, 2010 p. 4-38), que de forma clara e concisa, "dedica mais atenção às partes preliminares do processo, ou seja, àquelas associadas ao planejamento e ao projeto." Karlen, que pertence ao Programa de Mestrado em Belas Artes - Arquitetura de Interiores do Moore College of Art \& Design, Filadélfia - EUA, trata a etapa do processo de planejamento do ambiente nas fases preliminares, que se iniciam assim que "os problemas de projeto são apresentados ao projetista (com ou sem um programa de necessidades) e que termina quando o planejamento físico começa geralmente, com organogramas ou plantas baixas esquemáticas". A metodologia proposta por Karlen (2010) é composta das seguintes fases: (1) O processo de síntese; (2) O programa de necessidades; (3) A matriz de critérios; (4) Esboços de planta baixa; (5) O preenchimento da matriz de critérios; (6) Os diagramas de relações. A

"Metodologia de Planejamento", encerra-se quando se inicia o planejamento físico e o desenvolvimento

ErgodesignHCI, [S.1.], v. 6, n. Especial, p. 29 - 43, july 2018. ISSN 2317-8876. Disponível em:

<http://periodicos.pucrio.br/index.php/revistaergodesign-hci/article/view/526> Acesso em: 15 jan. 2020. 
PUC-Rio Pontifícia Universidade Católica do Rio de Janeiro Departamento de Artes \& Design | PPGDesign

LEUI | Laboratório de Ergodesign e Usabilidade de Interfaces

de plantas baixas, com todas as implicações espaciais e projetuais diversas - e a fase do planejamento de espaços e plantas baixas esquemáticas.

O método de Planejamento Espacial apresentado aqui, nasce a partir de um problema proposto e termina com a execução gráfica do projeto de interiores. É composta de uma estrutura divida em quatro fases: 1) levantamento de dados, análise e diagnoses sobre o território e o usuário; 2) elaboração de quadro resumo e quadro de funções, atividades, equipamentos e acessórios; 3 ) elaboração do conceito e partido para o projeto; 4) execução de esboços e do projeto gráfico final contemplando o conceito e o partido propostos.

A fase 1 e 2 , trata-se de uma etapa analítica e reflexiva onde o foco está centrado no território e no usuário; o processo ocorre de forma verbalizada e escrita, que são organizados através de planilhas e tabelas. A fase 3 tem o objetivo de gerar um conceito e um partido de projeto identificados com o perfil do usuário proposto. Em seguida, parte-se para elaboração gráfica do projeto com a prática de esboços, estudos prévios de layout, até chegar à representação gráfica final, conforme normas da ABNT - fase final do processo (fase 4).

A representação gráfica do projeto é elaborada manualmente, com instrumentos de desenho e acessórios complementares de colorir. Entende-se que a representação gráfica realizada manualmente (especialmente para os alunos iniciantes, como é o caso) através de esboços, croquis e desenho final, contribui significativamente para o desenvolvimento mental de habilidades. Este é um assunto controverso e não é objetivo deste artigo, contudo, corrobora-se com o pensamento de Lawson (2011), quando cita Donald Schön (1983) que explica "os desenhos fazem parte do processo mental de pensar projeto [...] o projetista realiza o ato de desenhar não para se comunicar com os outros, mas para seguir uma linha de pensamento. Conforme se desenvolve,

\footnotetext{
7 As Profas. Nora Geoffroy e Ecilia Cirne, do curso de Composição de Interiores da Escola de Belas Artes UFRJ, foram as idealizadoras da técnica de geração de dados, analises e diagnoses - sobre o território e o usuário, elaborando seu conteúdo, aplicando e desenvolvendo a técnica junto aos alunos das disciplinas de composição de interiores, testando e a aprimorando sua prática ao longo dos anos.
}

${ }^{8}$ Nota do autor: Neste artigo o termo território, afastase do natural entendimento que simplesmente refere-se a a imagem do desenho permite ao projetista "ver" novas possibilidades ou problemas". (LAWSON, apud SCHÖN, 2011 p. 246)

Esta prática metodológica de ensino projetual vem sendo aplicada, com algumas variações, como processo educativo no ensino de projeto de interiores, praticada no curso de Composição de Interiores (EBA-UFRJ), por professores das disciplinas de projeto já algum tempo ${ }^{7}$. Diante do fato que há muito pouco escrito sobre os métodos de planejamento espacial, principalmente do ponto de vista acadêmico, pretende-se antes de tudo, realizar um registro histórico do assunto, explicitar a aplicação do método, demonstrar a relação deste com os princípios básicos da ergonomia do ambiente construído e traçar algumas considerações sobre sua aplicação. Para melhor compreensão do método Planejamento Espacial, será explicitado em seguida algumas considerações sobre os termos território, usuário e conceito.

\section{1 - O Território}

Moraes (2005, p. 78) registrou alguns esclarecimentos sobre qual território ${ }^{8}$ tratamos. Inicialmente a autora cita Santos (1993) que explica território "é mais que um conjunto de objetos mediante os quais trabalhamos circulamos, moramos, mas também um dado simbólico". Mais a adiante a autora lembra as ideias de Siergfried Lenz, que nos diz que "território é o lugar onde temos as nossas raízes, onde possuímos nossa casa, falamos nossa linguagem, pulsamos nossos sentimentos mesmo quando ficamos em silêncio. É o lugar onde sempre somos reconhecidos".

Por fim, a autora chama a atenção para Fischer (1989) que estabelece uma distinção entre território e espaço pessoal: "espaço pessoal é uma zona móvel e invisível que circunda as pessoas; território é visível e estável." (MORAES apud SANTOS, FISCHER, 2005, p. 78)

uma área delimitada sob a posse de um animal, de uma pessoa (ou grupo de pessoas), de uma organização ou de uma instituição. E afasta-se mais ainda, quando o termo é empregado na política (referente ao Estado Nação, por exemplo), na biologia (área de vivência de uma espécie animal) e na psicologia (ações de animais ou indivíduos para a defesa de um espaço, por exemplo). 
PUC-Rio Pontifícia Universidade Católica do Rio de Janeiro Departamento de Artes \& Design | PPGDesign

LEUI | Laboratório de Ergodesign e Usabilidade de Interfaces

Seguindo a mesma linha de raciocínio vale destacar o sentido amplo da palavra lugar - que traduz satisfatoriamente de qual território tratamos neste estudo. Risério (2019, p. 26), aponta para as considerações do teórico norueguês Christian Norberg-Schulz, no livro Uma nova agenda para a arquitetura, através do texto $O$ fenômeno do lugar, onde o autor escolhe a palavra lugar como uma expressão concreta para falar do ambiente (natural ou construído).

Lugar é algo mais do que uma localização abstrata. É "uma totalidade constituída de coisas concretas que possuem substância material, forma, textura e cor". E é uma realidade que deve ser pensada em termos ecológicos e antropológicos, desde que mesmo os lugares destinados a abrigar as funções mais básicas da existência, como comer e dormir, variam segundo climas e culturas. É assim que nosso filósofo parte para analisar a "estrutura do lugar", que pode ser uma cidade, um bairro, uma rua, uma casa. (RISÉRIO, 2019 apud NESBITT, 2010).

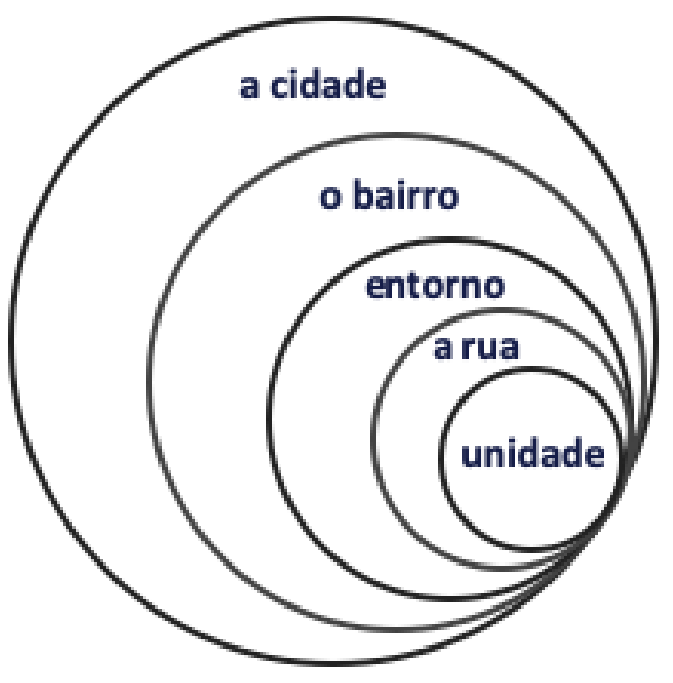

Fig. 1 TERRITÓRIO

Fonte: o autor

$\mathrm{Na}$ arquitetura o termo território aproxima-se da ideia de paisagem. Gregotti (2010, p. 62) defende o termo paisagem antropogeográfica, "indicando o ambiente modificado pelo trabalho ou pela presença do homem" - acepção comum e também presente em muitos textos de geografia. O termo também é empregado para caracterizar uma "área provisoriamente isolável e definível". O autor defende ainda que, "a realidade territorial é formada por uma série de estratos bastante complexos e interagentes (geográficos, administrativos, demográficos, econômicos, etc.), como realidades físicas que devem ser organizadas entre si com um objetivo comum que se concretizará numa nova forma do território.” (GREGOTTI, 2010, p. 87)

A investigação do território na aplicação do método de Planejamento Espacial consiste em compreender a interação do usuário com a cidade, o bairro, $o$ entorno imediato, a rua, o edifício e a unidade residencial (Fig. 01). A partir da técnica de observação (in loco) e análise de documentos específicos, levanta-se dados sobre: localização geográfica; características físicas e climáticas; aspectos históricos; patrimônio cultural (bens de natureza material e imaterial, paisagem cultural); aspectos físicos, econômicos, socioculturais; sistema viário, tráfego e meios de transporte; fluxos de pedestres; uso e ocupação do solo - institucional, comercial, residencial, misto; cobertura vegetal; microclima; passeios; ruídos; cobertura vegetal e iluminação pública. No edifício verifica-se aspectos tais como: acessibilidade, áreas comuns, formas de coleta de resíduos, número de pavimentos e unidades habitacionais circulações verticais e horizontais, orientação solar, materiais utilizados, envasaduras, entre outros. Por fim, na unidade habitacional, a partir da planta arquitetônica, faz-se uma análise minuciosa, sobre área construída, funções dos compartimentos, dimensões, pé-direito, vãos de ventilação e iluminação, paisagem, vãos de acesso (tipologia, material, dimensão); invasão de privacidade interna e externa - olfativa, auditiva e visual.

\subsection{O usuário}

Todo mundo é usuário, se considerarmos a relação do homem com o território e sua interação. Moraes (2011, p. 92-93) explica que o usuário não é um monólito. "Aquele que denominamos usuário é determinado por nossas perspectivas. Existe o usuário como uma abstração. Existe o usuário como sujeito de testes. Existe o usuário como um ideal que se deve considerar, e cujos limites e capacidades devemos incorporar ao projeto". De maneira geral, o usuário (cliente) é percebido pelos profissionais de projeto como valiosa fonte de informação. Contudo, seu papel vai além de demandador dos problemas. Acredita-se que ele faça parte do processo, atuando como fonte dos problemas e restrições do próprio projeto. Nesse sentido Lawson (2011) explica: 
PUC-Rio Pontifícia Universidade Católica do Rio de Janeiro Departamento de Artes \& Design | PPGDesign

Sem dúvida, é enganoso pensar que o cliente apresenta simplesmente ao projetista um resumo informativo completo, no qual o problema está totalmente definido e as restrições, articuladas com clareza. Na verdade, a própria relação entre cliente e projetista é uma parte significativa do processo de projeto. (LAWSON, 2011 p. 88)

Diferentemente da arquitetura de projetos de ordem pública (como hospitais, escolas, aeroportos, etc.), ou projetos comerciais (instituições, hotéis, condomínios, templos religiosos, etc.), e do design, que se propõem a um mercado de massa, onde os profissionais terão pouco contato com o usuário final, o designer de interiores, na maioria dos casos, trabalha diretamente com o cliente (usuário final ou não) - da mesma forma como ocorre com os clientes de projetos arquitetônicos residenciais ou corporativos, onde o próprio contratante é o cliente (e em muito dos casos, o usuário).

Neste tipo de relação cliente - designer de interiores prevalece um contato mais direto, muitas vezes edificando uma relação quase pessoal. Neste caso, o cliente procura o designer de interiores, a partir de uma situação problema (uma reforma, um imóvel novo, uma readequação de um espaço existente, uma consultoria etc.), em busca de uma solução projetual. Quando o cliente não é o usuário final, o designer de interiores evoca (assim como ocorre na arquitetura) conhecimentos das ciências humanas e sociais, como ergonomistas, psicólogos, sociólogos, etc. para saber aquilo que realmente os usuários precisam. Embora seja de grande valia essa aliança entre projetos e os conhecimentos das ciências sociais e humanas, há ruídos na relação entre o cliente (contratante), o usuário final e os profissionais de interiores. Observa-se que de maneira geral o usuário final - em se tratando de projetos de interiores, pode ser a (o) empregada (o) doméstico, o(a) filho(a) do casal, ou qualquer ente da família que não participou das discussões do projeto, que, na maioria das vezes, permanece afastado dos profissionais de interiores, e a relação é tratada diretamente, quase sempre, com o cliente (contratante). Neste caso, o cliente assume a tarefa de interlocutor dos desejos e necessidades das pessoas e entes que não tratarão diretamente com os profissionais contratados.

Na disciplina de Composição de Interiores I, por razões pedagógicas, faz-se uso de um usuário ficcional. O professor da matéria desenvolve uma história fictícia onde propõe uma persona com características particulares de vida pessoal e profissional, valores, hábitos, rotinas e suas principais atividades. Estes dados são analisados em separado e mais tarde faz-se os cruzamentos necessários com os dados obtidos a partir da análise do território estudado considerando os aspectos pragmáticos, funcionais, ergonômicos, culturais e simbólicos. Nesse sentido, investiga-se sobre o usuário proposto: idade, sexo, origem - história pessoal; profissão/ocupação; características pessoais, temperamento, valores; rotina, hábitos - o cotidiano: sono, alimentação e trabalho; lazer: hobbies, colecionismo, entretenimento; relações pessoais - família, amigos; usuários da moradia funcionários e prestadores de serviço; equipamento mobiliário, acessórios e objetos de arte existentes; demandas; qualificação da ambiência.

Os dados de território e usuário são organizados em planilha onde registra-se as informações levantadas que geram análises sobre a relação do aspecto espacial e o usuário. Estas análises possibilitam ao aluno realizar reflexão avaliativa, confronto de informações e cruzamento de diferentes dados, somados ao repertório pessoal do profissional. Em seguida, a partir das análises realizadas, geram-se diagnoses, que podem determinar ações que irão balizar as possíveis soluções projetuais.

\section{A ergonomia do ambiente construído $x$ usabilidade}

Apesar de seu recente fortalecimento - vide o número de publicações em sessões e congressos específicos da área, vale destacar que conforme Moraes (2005 p. 68 apud Fraser, 1983 apud Buti, 1998) a Ergonomia trata do "estudo das características anatômicas, fisiológicas e psicológicas dos indivíduos no ambiente de trabalho, com a finalidade de gerar segurança, saúde, conforto e eficácia aos seus níveis otimizados." A Ergonomia ocupa-se não só da relação do homem com o objeto, mas também da relação do homem com o ambiente onde está inserido. Conforme explica Moraes (2005. p. 68, apud Buti, 1998) "a Ergonomia do Ambiente Construído deve ocupar-se de quem usará, que coisa será usada, mas principalmente onde virá a ser usada. O onde é o ambiente de destinação que deve ser analisado como lugar físico e sócio cultural que condiciona a interação entre o homem e o objeto."

Considerando-se os enunciados acima, destaca-se neste estudo a importância das análises dos aspectos de usabilidade entre o usuário e o território 
(ambiente) na metodologia de planejamento espacial. Neste conciso texto, o termo usabilidade é compreendido mais além que apenas sobre o nível de facilidade de uso de um produto. Faz-se aqui uso da definição da ISSO - International Standarts Association, que define usabilidade como " $a$ efetividade, eficiência e satisfação com os quais usuários específicos atingem metas específicas em ambientes particulares" (ISSO 9241-11, 2018).

Para elucidar a aplicação do termo nas análises que são realizadas durante o uso da Metodologia de Planejamento Espacial, utiliza-se o mesmo entendimento de Moraes (2005, p. 11 e 12) que explica sobre os três aspectos: (1) efetividade - que se refere à extensão em que uma meta ou tarefa é alcançada. Para a ergonomia do ambiente construído "têm-se a capacidade de se movimentar de um ponto ao outro e desempenhar suas tarefas", como por exemplo os pontos de movimentação de uma dona de casa em sua cozinha, desempenhando determinada tarefa entre os pontos clássicos de funcionalidade: preparo/lavagem, cocção e armazenamento; (2) eficiência - se refere à quantidade de esforço que o indivíduo investe para atingir a sua meta. No que se refere a eficiência "no âmbito da ergonomia do ambiente construído, além do ir de um ponto ao outro do espaço, considera-se a economia de tempo e a segurança." Ainda no mesmo exemplo, melhorar as distâncias através da otimização do layout, para que a dona de casa percorra menos espaços entre os pontos de funcionalidade da cozinha, desprendendo menos esforços e otimizando o tempo; por fim, (3) satisfação - se refere ao nível de conforto e de aceitabilidade dos usuários ao usar produtos. Tratase de um aspecto mais subjetivo, pois depende da avaliação e experiência pessoal do usuário. $\mathrm{Na}$ ergonomia do ambiente construído, "pode-se ter a satisfação com a paisagem, com a tranquilidade do ambiente, com a estética do ambiente construído, etc." No nosso exemplo da dona de casa e sua cozinha, não alcançaríamos níveis elevados de usabilidade se por acaso, o ambiente não considerasse também, aspectos relativos ao conforto ambiental, valorização da estética, entre outros.

As análises e diagnoses realizadas na metodologia de planejamento espacial, no âmbito da ergonomia

${ }^{9}$ OLIVEIRA, Gilberto Rangel; MONT'ALVÃO, Claudia Renata. O Processo de Projeto de Interiores e o uso da Ergonomia na prática segundo a visão de profissionais e usuários. Revista ErgodesignHCI, [S.1.], v. 5, n. Especial, p. 61 - 72, dec. 1969. ISSN 2317-8876. do ambiente construído, visa observar a usabilidade como importante aspecto a ser considerado, que deve facilitar as atividades dos usuários, seja nas suas rotinas cotidianas, no trabalho ou lazer. Aspectos específicos de análise ergonômica no ambiente construído devem ser observados quando analisamos o usuário e o ambiente, conforme artigo já publicado anteriormente. ${ }^{9}$

\section{A Metodologia de Planejamento Espacial - Aplicação}

A metodologia de planejamento espacial na disciplina Composição de Interior I, inicia-se com a investigação do território existente considerando a interação do usuário com a cidade, o bairro, $o$ entorno imediato, a rua, o edifício e a unidade residencial. A partir da técnica de observação (in loco) e análise de documentos específicos, levantase dados sobre: localização geográfica; características físicas e climáticas; aspectos históricos; patrimônio cultural (bens de natureza material e imaterial, paisagem cultural); aspectos físicos, econômicos, socioculturais; sistema viário, tráfego e meios de transporte; fluxos de pedestres; uso e ocupação do solo - institucional, comercial, residencial, misto; cobertura vegetal; microclima; passeios; ruídos; cobertura vegetal e iluminação pública. No edifício verifica-se aspectos tais como: acessibilidade, áreas comuns, formas de coleta de resíduos, número de pavimentos e unidades habitacionais circulações verticais e horizontais, orientação solar, materiais utilizados, envasaduras, entre outros. Por fim, na unidade habitacional, a partir da planta arquitetônica, faz-se uma análise minuciosa, sobre área construída, funções dos compartimentos, dimensões, pé-direito, vãos de ventilação e iluminação, paisagem, vãos de acesso (tipologia, material, dimensão); invasão de privacidade interna e externa - olfativa, auditiva e visual.

Os dados devem ser enriquecidos com informações levantadas a partir de leis, decretos, normas, publicações oficiais e dados obtidos de fontes fidedignas, como sites institucionais (público e/ou privado), publicações, periódicos e associação de moradores de bairro, por exemplo. Diante dos dados

Disponível em: <http://periodicos.pucrio.br/index.php/revistaergodesign-hci/article/view/351>. Acesso em: 15 sep. 2019. 
PUC-Rio Pontifícia Universidade Católica do Rio de Janeiro Departamento de Artes \& Design | PPGDesign

levantados, inicia-se as análises que são realizadas considerando-se os dados observados in loco, e sua relação com os documentos pesquisados. Através do cruzamento dos diversos dados mapeados em uma planilha, realiza-se as mais diversas análises considerando-se aspectos pragmáticos, funcionais, simbólicos e culturais.

A etapa seguinte é elaboração de diagnoses, que são as ações projetuais que podem ser realizadas visando o melhor entendimento entre as necessidades do usuário e sua relação com o espaço. Organiza-se o processo por seções. Assim há diagnoses propostas no planejamento da relação usuário e a cidade, usuário e o bairro, usuário e a rua; usuário o edifício e usuário e a unidade habitacional.

Todos os dados, análise e diagnose da metodologia de planejamento espacial são organizados em um formulário, tipo planilha, onde o aluno pode visualizar por seções as relações entre o usuário e o ambiente de forma organizada e clara.

\section{1 - Quadro de resumo geral}

Procede-se então após a realização das análises e diagnoses, a elaboração de uma síntese de documento, chamado de quadro resumo geral, onde o mesmo auxilia o projetista no próximo passo para a elaboração do conceito de projeto.

Através da aglutinação de palavras e fatos (ou temas), este quadro ajuda a determinar aspectos que o designer deve selecionar a partir dos estudos e observações de palavras que ocorrem com mais frequência, que consequentemente, permitirão ao projetista uma ideia global que o conduzirão a um projeto coerente.

Além disso, para melhor visualização e compreensão do designer sobre o usuário e o território o quadro resumo é dividido em aspectos técnicos e culturais, sendo esse último subjetivo para o cliente. Desta forma, é possível enfatizar os dois aspectos no projeto para que assim seja o mais particular possível para o usuário.

\section{2 - Quadro de Funções, Atividades, Equipamentos e Acessórios - QFAEA}

A elaboração deste quadro nos permite tratar sobre as funções pragmáticas das atividades e equipamentos necessários ao projeto, listando-se as funções específicas de cada dependência/compartimento ou espaço do programa.

A Função dá-se pela adaptação objetiva da organização do espaço e dos aspectos ergonômicos ligados a relação entre usuário e ambiente ou homem e seu trabalho, aplicando-se conhecimentos de anatomia, fisiologia e psicologia na solução dos problemas sugeridos. Equipamento, é tudo aquilo que integra o espaço, equipando-o com utensílios, objetos, móveis etc. É tudo aquilo que serve para equipar a habitação. Acessório é aquilo que se junta ao objeto principal ou é dependente dele, contribuindo secundariamente, para a harmonia do ambiente, e também a níveis sensoriais e ergonômicos, tornando-se um utensílio facilitador do desempenho de uma atividade.

Como resultado, temos o enriquecimento do programa do cliente e a ampliação das possibilidades de acerto no projeto, na seleção de equipamentos e materiais a serem utilizados, e diminuir a possibilidade de esquecimento de algum objeto e equipamento essencial. Neste processo, os valores ou Funções Simbólicas dos aspectos semióticos do Design, são tratados através dos aspectos históricos, culturais e territoriais, valores particulares e crenças que ligam o usuário ao projeto, confirmando a necessidade de uma particularização de projetual a fim de melhor adaptação do projeto ao usuário.

\section{3 - O Conceito}

Os resultados das análises dos dados levantados e as diagnoses realizadas, no método de Planejamento Espacial produzem um número elevado de informações que o aluno deve aprimorar e reorganizar através de resumos estendidos. É fundamental a análise atenta do aluno para destacar os aspectos que irão de fato contribuir com soluções projetuais adequadas e descartar informações que podem não ser necessárias para esta fase de planejamento espacial.

Objetiva-se nesta fase do trabalho formular um conceito que traduza a concepção formal do projeto. Nesse sentido, entende-se conceito como uma "representação mental de um objeto abstrato ou concreto que se mostra como instrumento fundamental do pensamento em sua tarefa de identificar, descrever e classificar os diferentes 
elementos e aspectos da realidade." (HOUAISS, 2009).

Coelho (2011, p. 168) explica que "conceito se estabelece a partir da compreensão e extensão de um objeto, englobando seus atributos, qualidades e elementos constitutivos." Nesse sentido, entende-se que a correta compreensão e elaboração das análises e diagnoses, realizados no método de Planejamento Espacial sobre determinados dados, poderão contribuir significativamente com o enriquecimento do conceito proposto pelo aluno.

Gibbs (2014) apresenta uma visão mais mercadológica e pragmática no processo de elaboração do conceito e explica que "alguns profissionais baseiam o processo criativo em um fato concreto e trabalham principalmente com a análise do projeto." Desta forma cita o exemplo que o designer pode solicitar ao cliente três palavras que transmitam as características desejadas, como leveza, elegância e conforto. Como alternativa, lembra que "outros profissionais podem buscar inspiração nos elementos naturais próprios do local onde o imóvel se localiza". (GIBBS 2014, p. 62)

Por fim, Gibbs (2014) chama atenção para "ao estabelecer o conceito de projeto, o designer deve levar em consideração as limitações de fatores como o orçamento, o próprio imóvel e o estilo de vida do cliente." Tais considerações demonstram a visão pragmática e comercial da autora, que apesar de significativos, no entender dos autores deste artigo, corre-se o risco de resvalar em conceitos repetitivos e que talvez, traduzam menos a identidade do usuário na concepção formal do projeto.

\section{Considerações Finais}

A metodologia de planejamento espacial visa compreender as relações entre o território e usuário como pano de fundo para um exercício projetual. Trata-se de uma ferramenta metodológica que, devido ao formato proposto, é construída entre todos os participantes do processo: alunos e o professor da disciplina. Como explicitado acima, faz uso de um território real e um usuário fictício inédito, elaborado pelo professor. Face a exposição realizada, traça-se algumas considerações que tem o objetivo de destacar vantagens e desvantagens do uso dessa ferramenta metodológica - pedagógica. Também, em oportuno, realiza-se o registro de como as disciplinas de projeto são estudadas no referido curso.
- O aspecto quantitativo e qualitativo dos dados levantados, depende do empenho dos alunos e da orientação efetiva do professor da disciplina;

- As análises e diagnoses precisam ser exaustivamente estimuladas junto aos discentes, considerando que a pouca experiência em análises de dados e reflexões, constituem-se como um problema de formação acadêmica endêmico;

- A dinâmica de aplicação e elaboração da planilha do método de planejamento espacial, realizado de forma colaborativa em grupo, favorece a participação dos discentes que se sentem estimulados a contribuir para a construção do trabalho e troca de ideias;

- Considerando o número de itens o trabalho muita das vezes torna-se exaustivo;

- A qualidade dos dados e as análises adequadas irão gerar diagnoses úteis para etapas seguintes do projeto;

- A deficiência no levantamento dos dados, bem como análises mal estruturadas, irá gerar diagnoses deficientes, o que pode comprometer as etapas seguintes do projeto;

- A experiência do docente na aplicação do método de planejamento espacial, é um atributo a ser considerado de forma positiva;

- Percebe-se que quanto maior o empenho dos alunos na realização das análises e diagnoses, consequentemente, surgem conceitos mais elaborados e muitas das vezes, a execução gráfica do projeto demonstra criatividade e elevado grau de pertinência ao usuário.

- Os conceitos elaborados a partir da planilha elaborada no método de planejamento espacial, tem demonstrado importante subsídio como ferramenta para criação de conceitos elaborados que favorecem as etapas seguintes do projeto.

- Através da aplicação contínua do método, busca-se o constante aperfeiçoamento. Planejase realizar a análise da metodologia em outros cenários de uso coletivo, como projetos comerciais, institucionais, etc. 
PUC-Rio Pontifícia Universidade Católica do Rio de Janeiro Departamento de Artes \& Design | PPGDesign

LEUI | Laboratório de Ergodesign e Usabilidade de Interfaces

A ação projetual é uma atividade complexa. $\mathrm{O}$ projeto requer uma atuação criativa, acúmulo de informação, conhecimento e alguma experiência. Enfrenta desafios complicados, como definir com precisão os reais problemas dos usuários e planejar possíveis soluções, considerando níveis de necessidades a serem atendidos.

Ribeiro e Mont'Alvão (2005, p. 87) são taxativas em afirmar que "é importante observar e registrar como o usuário do ambiente o percebe e o experiência". Explicam que isto significa "compreender em que medida o desempenho do ambiente construído influencia o comportamento do usuário, mas também como este se molda aquele desempenho, modificando ou não esse ambiente, no decorrer de seu uso, dando origem assim a um novo padrão de ambiente construído". A metodologia de análise espacial, possibilita uma investigação crítica e rica de aspectos do campo funcional e simbólico da interação entre usuário e ambiente. Acredita-se que os conceitos e ideias concebidos irão traduzir um projeto único e específico para cada usuário.

\section{Referências Bibliográficas}

\section{BITENCOURT, F. Ergonomia e Conforto}

Humano - Uma visão da arquitetura, engenharia e design de interiores. Rio de Janeiro: Rio Books, $2^{\mathrm{a}}$ ED. 2017.

BROOKER, G. \& STONE, S. O que é design de interiores. Tradução: André Botelho. São Paulo: Senac, 2014. Título Original: What is interior design?

\section{COELHO, L. A. (org.). Conceitos-chave em} design. Rio de Janeiro: 2AB / Novas ideais, 2011.

DEJEAN J. O século do conforto. Quando os parisienses descobriram o casual e criaram o lar moderno. Tradução: Catharina Epprecht. Rio de Janeiro: Civilização Brasileira, 2012. Título original: The Age of Comfort: When Paris discovered casual - and the modern home began, 2009.

GEOFFROY, N. A Metodologia em projeto de interiores: o papel do briefing na elaboração do conceito. Rio de Janeiro: UFRJ - EBA INTERIORES. 2015.

GIBBS, Jenny. Design de interiores: guia útil para estudantes e profissionais. Tradução Claudia
Ardión. Barcelona: Gustavo Gili, 2014. Título original: Interior Design

GREGOTTI, Vittorio. Território da Arquitetura. Tradução Berta Waldman e Joan Vila. $3^{\mathrm{a}}$ ed., $3^{\mathrm{a}}$ reimpr. São Paulo: Perspectiva, 2010. Título original: Il território dell Architectura

HOUAISS, A. Dicionário Houaiss da língua portuguesa. Rio de Janeiro: Objetiva, 2009

ISO 9241-11:2018 Ergonomics of human-system interaction -- Part 11: Usability: Definitions and concepts. Disponível em:

https://www.iso.org/obp/ui/\#iso:std:iso:9241:-11:ed2:v1:en. Acesso em: 15. sept. 2019

KARLEN, Mark. Planejamento de espaços internos. Tradução: Alexandre Salvaterra. 3ed. Porto Alegre: Bookman, 2010. Título original: Space Planning Basics

LAWSON, B. Como arquitetos e designers pensam. Tradução: Maria Beatriz Medina. 2 ed. São Paulo: Oficina de textos, 2011. Título original: How designers think: the design process demystified.

MORAES, A. de (org.) Ergodesign do ambiente construído e habitado. Rio de Janeiro: $2 \mathrm{AB}, 4^{\mathrm{a}}$ ed. 2005.

MORAES, A. de. Usuário. In: COELHO, Luiz Antônio (org.). Conceitos-chave em design. Rio de Janeiro: 2AB/Novas ideias, 2011. p. 92-93.

PAZMINO, A. Como se cria. 40 métodos para design de produtos. São Paulo: Blucher, 2015

RIBEIRO, Lúcia e MONT'ALVÃO, Claudia. Ergonomia do Ambiente Construído: teoria e prática. In: MORAES, Anamaria (org.). Ergodesign do ambiente construído e habitado. Rio de Janeiro: $2 \mathrm{AB}, 4^{\mathrm{a}}$ ed. 2005

RISÉRIO, Antonio. A casa no Brasil. Rio de Janeiro: Topbooks, 2019, p. 26

ROOZENBURG, N. F. M. e EEKELS, J. Product Design: Fundamentals and methods. West Sussex, UK: John Wiley \& Sons, 1995.

SILVA, E. Uma introdução ao projeto arquitetônico. Porto Alegre: Editora UFRGS, 1998 


\section{Agradecimentos}

À Universidade Federal do Rio de Janeiro - UFRJ, em especial à Escola de Belas Artes e o corpo docente e discente do curso Composição de Interiores, que tem contribuído para interessantes experiências acadêmicas. 